Haya: The Saudi Journal of Life Sciences

Abbreviated Key Title: Haya Saudi J Life Sci ISSN 2415-623X (Print) |ISSN 2415-6221 (Online) Scholars Middle East Publishers, Dubai, United Arab Emirates Journal homepage: http://scholarsmepub.com/haya/

Original Research Article

\title{
Characterization of Selected Plants Leaves with Particular Emphasizes on Epidermis
}

\author{
A Raza ${ }^{1}$ Iqra $^{2}$, U. Ghani ${ }^{1 *}$, N. Azhar ${ }^{1}$, I. Hussain ${ }^{1}$, M. U. Khan $^{1}$, S. Bano ${ }^{1}$, A. Rubab ${ }^{1}$, S. N. Sajid ${ }^{1}$, S. A. H. Bukhari ${ }^{1}$, Z.

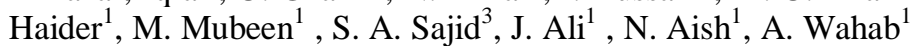 \\ ${ }^{1}$ University of Agriculture, Faisalabad, 38000, Pakistan \\ ${ }^{2}$ University of Gujrat, Punjab, 50700, Pakistan \\ ${ }^{3}$ University of Lahore, Punjab, 54570, Pakistan
}

DOI: $\underline{10.36348 / \text { SJLS.2019.v04i09.006 }}$

| Received: 21.10.2019 | Accepted: 28.10.2019 | Published: 30.10 .2019

*Corresponding author: Usman Ghani

\section{Abstract}

The leaves of most plants contain two highly differentiated cell types in the epidermis guard cells, which constitute stomata, and trichomes. These cells, the spacing of which is the primary focus are usually separated from each other by pavement cells. Our understanding of the response of angiosperm stomata to environmental parameters remains imprecise because we know little about the mechanisms of stomata control modules. This research was carried out in the old Botanical Garden of the Agriculture University, Faisalabad from January 2019 to June 2019 to examine morphological studies of selected dicots plants leaves with biological active compounds for treatment of cancer using the compound light microscope also to predict algometric relationships between morphologically stomata traits in relation to gaseous exchange in leaf and required allocation of epidermal area to stomata. Epidermal cells varied from round, square to hexagonal with distinctive anticlinal cell wall and sunken stomata distributed on adaxial and abaxial were observed. Stomata are present in the upper and lower surface of the leaves helpful as adaptation for plants during photosynthesis process and stress condition to maintain the water usage.

Keywords: Paracytic, Anomocytic, Abaxial, Crucuferious, Photosynthesis.

Copyright @ 2019: This is an open-access article distributed under the terms of the Creative Commons Attribution license which permits unrestricted use, distribution, and reproduction in any medium for non-commercial use (NonCommercial, or CC-BY-NC) provided the original author and source are credited.

\section{INTRODUCTION}

The epidermis of plant leaves provides an excellent system for analyzing pattern formation because the epidermal surface is readily accessible and cell patterns can be analyzed within a plane rather than in three dimensions. The leaves of most plants contain two highly differentiated cell types in the epidermis: guard cells, which constitute stomata, and trichomes. These cells, the spacing of which is the primary focus of this review, are usually separated from each other by pavement cells [1].

The general role of botanic gardens in plant conservation has been widely accepted since the 1970 and many threatened plant species are now in welldocumented living collections and seed banks. Conserving tree species in ex situ collections still presents particular challenges. Many trees have socalled 'recalcitrant' seeds that cannot be stored in conventional seed banks and the sheer size of living trees restricts the number of individuals of a particular species that can be grown in a botanic garden. Even if space is available, is ex situ conservation a desirable option and how does this compare with conserving tree species in their natural habitats. Various cancer such as breast cancer and gut cancer have been rapidly increasing in world [2]. Clearance of forest for agriculture and mining, logging for timber and overgrazing of woodlands have all contributed to the decline of tree species in the wild. Climate change is adding an additional overarching threat to species with limited distributions, such as trees that are endemic to the cloud forests of Mexico [3].

Climate change is also likely to pose particular problems for tree species with poor regeneration and dispersal mechanisms that consequently are unable to migrate fast enough in responseto climatic shift. Currently, the IUCN Red List includes 6227 tree species that are threatened with extinction in the wild. Of these, 1002 tree species are recorded as Critically Endangered, the most threatened category for species based on the risk of extinction [4]. Conservation assessments have not yet been undertaken for many 
other tree species. All tree species, including those that are known to be at risk of extinction, are important components of ecosystems. They contribute to the sequestration of anthropogenic carbon dioxide and provide other ecosystem functions, such as soil stabilization and regulation of surface. Trees also provide a range of resources for human livelihoods including timber, fuel wood, medicines and food [5]. These resources are diminishing as tree species decline in the wild and action is needed to ensure sustainable use and long-term species conservation. In a transpiring leaf, vapor lost from the leaf interior to the atmosphere must be replenished via the vasculature by groundwater absorbed by the roots. An imbalance results in either stomatal closure and no $\mathrm{CO} 2$ capture or risk of cavitation due to negative water pressures. Positive correlation exists between the potential for water supply to the leaf and gas exchange capacity [6].

Mesophyll resistivity is higher than xylem resistivity, minimization of the mesophyll path length (dm) improves hydraulic conductance. This can most readily be achieved by increasing vein density is measurable in living and fossil leaves and scales inversely with and can provide an approximation for $\mathrm{dm}$ and consequently Kleaf. In studies encompassing a broad range of character variation, gas exchange capacity correlates [7].

A less prevalent consideration is that the tissues linked to vasculature - and, thus, hydraulic conductance, also can entail the exclusive occupation of epidermal space. Stomata are frequently absent in the epidermis overlying vein paths due to the tight packing of parenchyma cells extending to the epidermis from the vascular bundle sheath. This is a general feature in large veins that protrude beyond the thickness of the leaf lamina, but thinner veins that do not protrude can also involve a column of tightly packed cells that extend from the vascular bundle sheath to the epidermis. This bundle sheath extension (BSE) precludes mesophyll airspace, thereby excluding stomata. In angiosperms, major veins occur at very low densities over the leaf (over one-order of magnitude lower than Dv: cf). However, BSEs will be shown to cover a wide range of values [7].

Stomatal pores in the aerial epidermis not only possess immense ecological significance but also represent one of the most consistent micro morphological features in the evolutionary history of land plants. Stomata occur in the majority of land plants, almost exclusively on the sporophyte, although stomata have occasionally been reported on the gametophyte of the extant model fern Ceratopteris [8]. Almost invariably among post devonianembryophytes, each individual stoma consists of a symmetric pair of guard cells delimiting a central pore, although rare exceptions include the moss Funaria. By contrast, the stomata complex which by definition encompasses the guard cells plus neighboring epidermal cells. Stomata development has been studied since the early work was extensively inferred in fossil seed plants by the influential Swedish palaeobotanist Rudolf Florin. Florin famously identified two contrasting patterns of stomatal complexes in gymnosperms (both fossil and extant), which he termed haplocheilic and syndetocheilic [9].

The main aims oh this research is to carry out epidermal patterns in different plants with special micro examination at higher level. Paralytic stomata one of the features that group bennettites with angiosperms in morphological cladistics analyses of seed plants [10]. However, the lateral subsidiary cells of paralytic stomata can be either perigene, as in grasses ormesogene, as in some other angiosperms such as Magnolia and in the early divergent pteridophyte Equisetum [9]. Some metals causes toxicity which also leads to plant tissues damages and ultimately death [11].

\section{MATERIALS AND METHODS}

The materials were used in this research included plants with suitable leaves. Smooth leaves without many leaf hairs are usually best, compound microscope with magnification up to $400 x$, microscope slides, coverslips, water dropper bottle or beaker and transfer pipette, forceps and scalpel blades, marker pen, digital camera to capture microscope images of the leaf surfaces and this greatly aids in counting stomata and is a record of the results for future reference

\section{Analysis of Samples}

Collect a suitable leaf and all other materials. Label a microscope slide. Bended the leaf to break the surface or tear the leaf from the edge .Tear off some epidermis, the transparent thin layer of surface cells. Cut the epidermal layer from the leaf, place on a microscope slide. Add a drop or two of water. Place a coverslip on the sample. View under the compound light microscope at an appropriate magnification (usually $100 x$ or $400 x$ ). In an unstained epidermis it helps to close the iris diaphragm a little to increase contrast and see the cell walls clearly [12]. The limitations of this method includated not all leaves are easy to peel and frequently mesophyll cells come off with the epidermal layer, giving more than one cell layer and making identification of the epidermal cells difficult and confusing

\section{RESULTS}

On the basis of careful microscopic examination fine and smooth surface of epidermis was observed. The stomata on the epidermal cells of leaves evenly distributed on the lower and upper epidermal surfaces. The stomata were very numerous and deeply sunken below the surface of leaf. Different type of stomata carefully observed for microscopic examination of epidermis of the plants. Mesogenous stomata in which the subsidery cell have the cooonorigin with 
guard cells and other is the Perigenous which develop from the protodermal cells. Different type of the stomatal shapes has been observed during the research works that are similar in shape to the shape of the dicots plants epidermis shown. These are like the anomocytic type in that guard cells are surround by many similar in size and shape to the epidermal cells means here no subsidery cells are found. Crucuferious type show that guard cells are surrounded by three subsidery cells of unequal size. Paracytic type show that guard cells accompanied by one or more subsidiary cells parallel to axes. Diacytic type in which stomata surround by the two subsidery cells. These shapes of the cells are shown under the microscope.
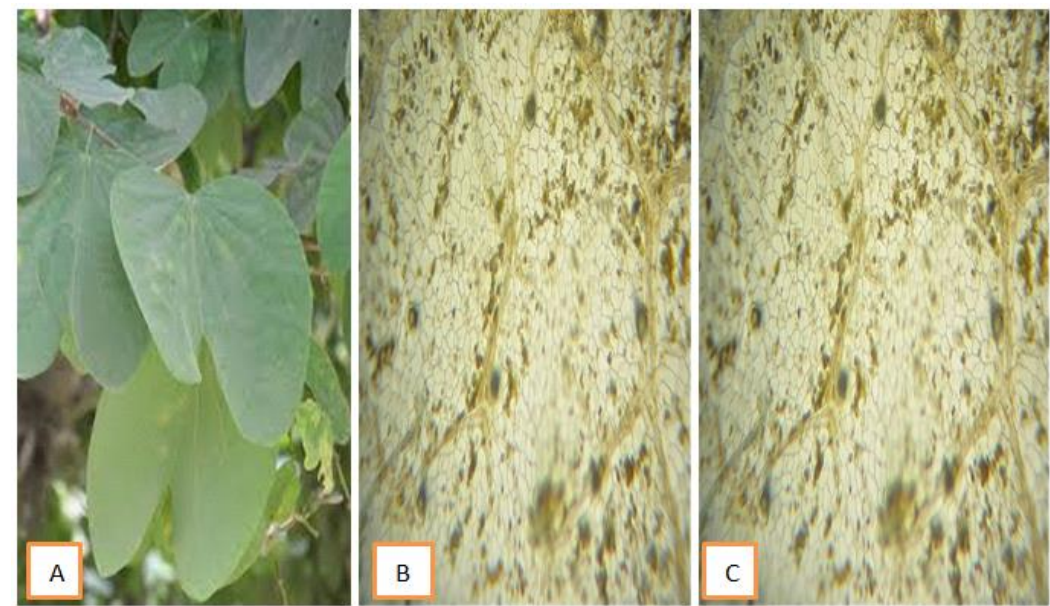

Fig-1: (A) Leaf Shape of Bauhinia variegate; (B) Upper Surface; (C) Lower Surface
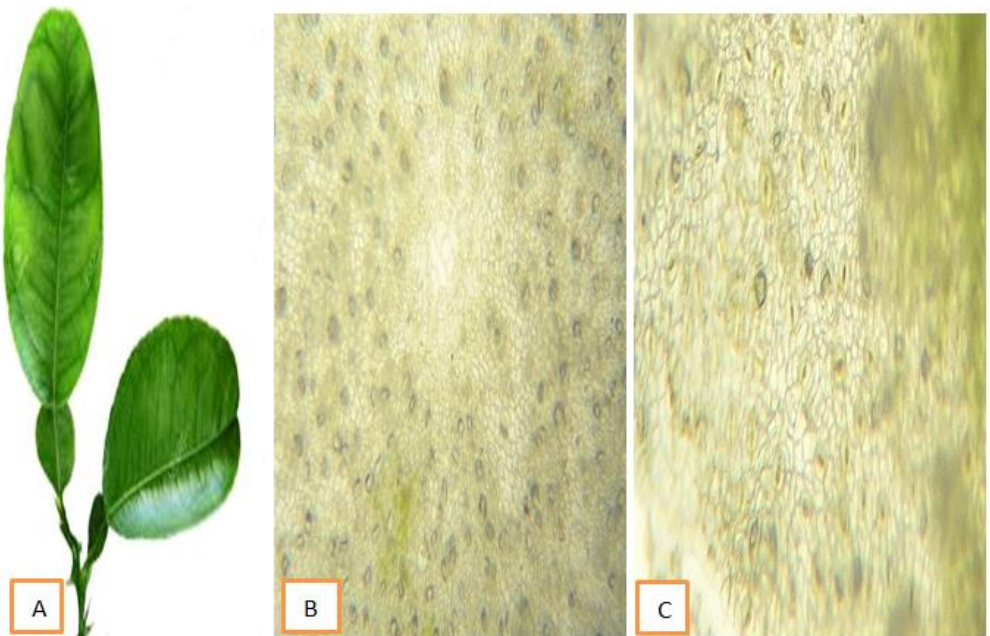

Fig-2: (A) Leaf Shape of Citrus limon; (B) Upper Surface; (C) Lower Surface
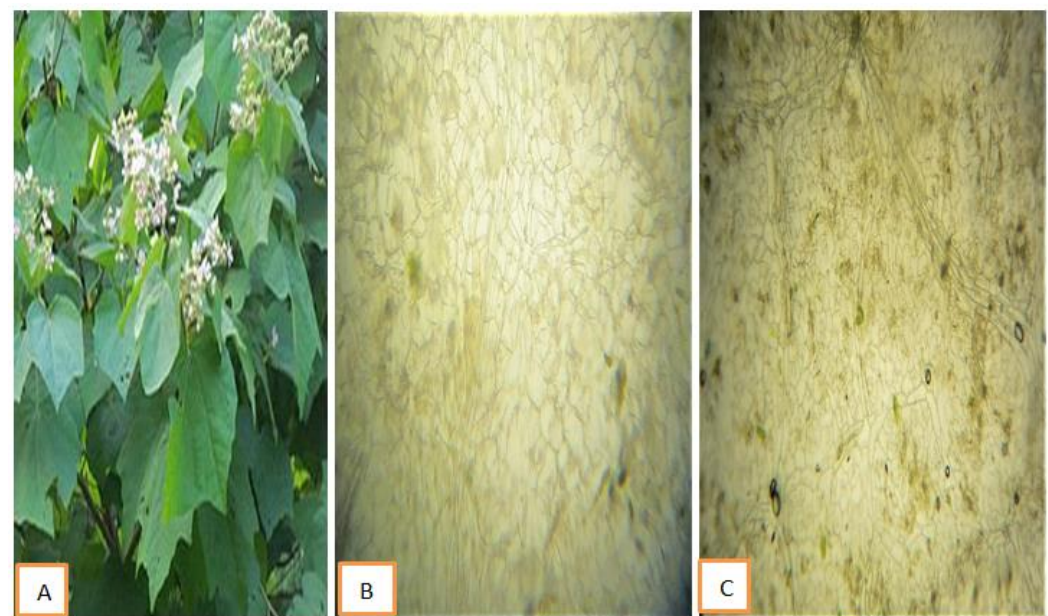

Fig-3: (A) Leaf Shape of KydiaCalycina; (B) Upper Surface; (C) Lower Surface 

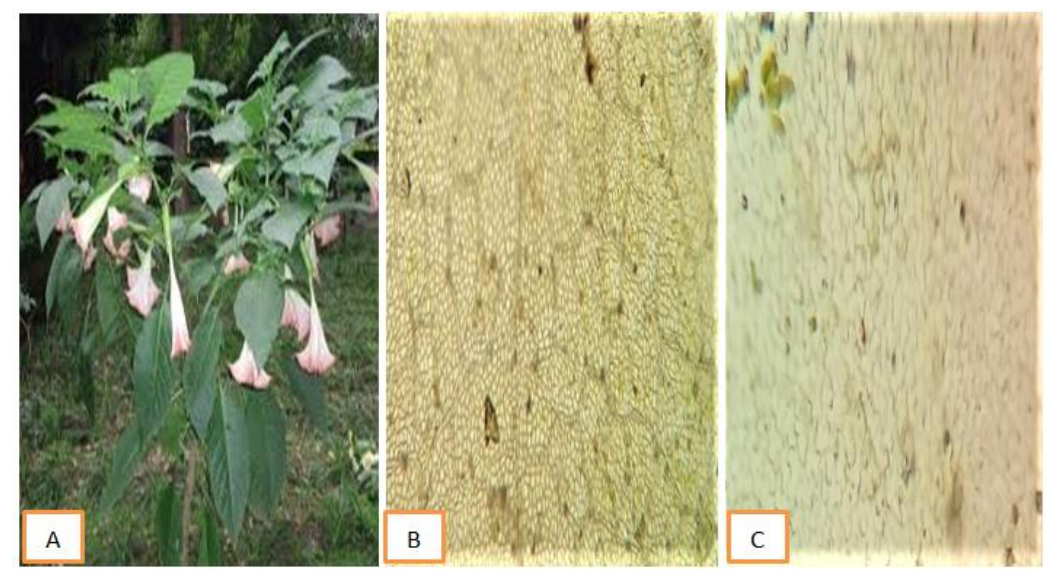

Fig-4: (A)Leaf Shape of Brugmansiasuaveolens(B)Upper Surface (C) Lower Surface
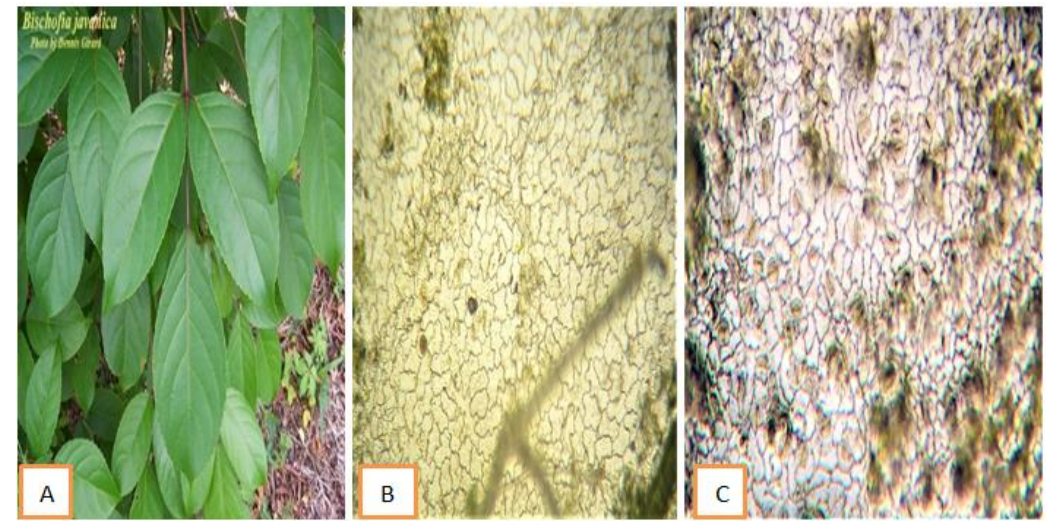

Fig-5: (A)Leaf Shape of Bischofiajavanica; (B)Upper Surface; (C) Lower Surface
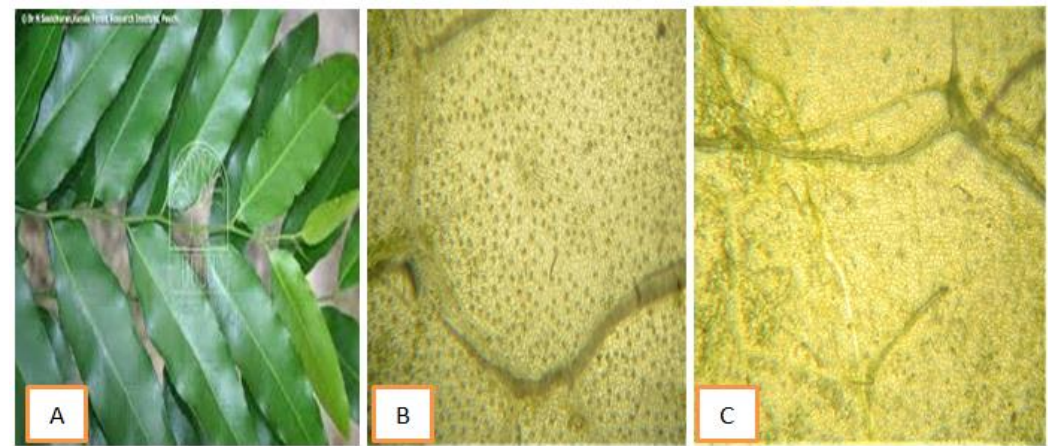

Fig-6: (A)Leaf Shape of Putranjivaroxburghii; (B)Upper Surface; (C) Lower Surface
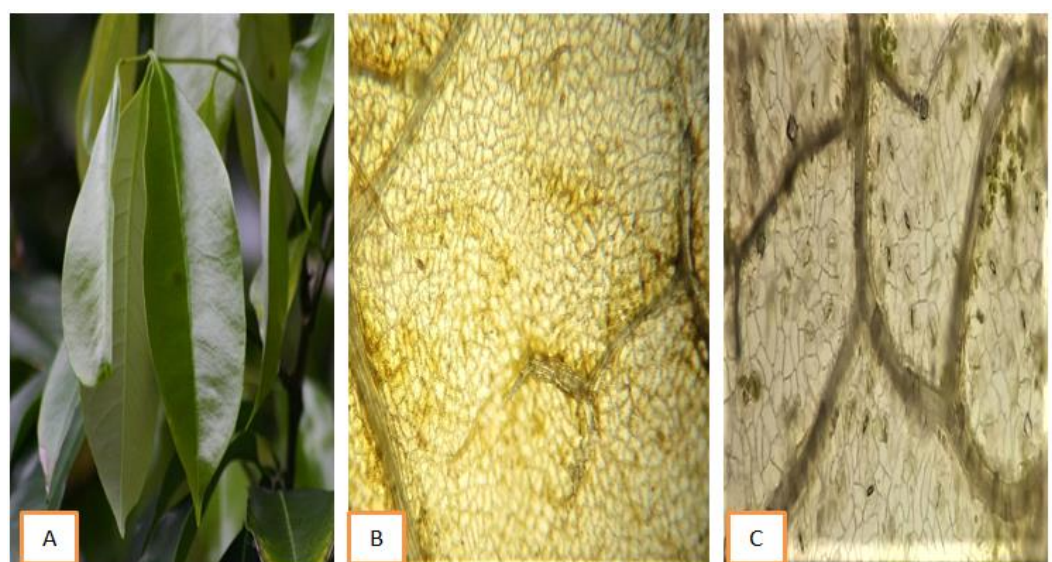

Fig-7: (A)Leaf Shape of Litchi chinensis; (B)Upper Surface; (C) Lower Surface 


\section{DISCUSSION}

Our research suggests that gradually changes in shape of stomatal traits provide an evidence to increase the gas exchange capacity of epidermis although deceases the division of the epidermis that is covered with stomata. Several epidermal traits in the bennettitales with the characteristic of thickenings of guard cell wall correspond to both ecologically and physiological character [13]. Epidermal cells that contain anticlinal walls with lobed are extremely indication of adaxial or abaxial differentiated mesophyll with the purpose of balanced the rate of photosynthesis also provides mechanical strength. Bennettite leaves show polarity that influenced by genetic factors alike to those that controlling the polarity of abaxial and adaxialin angiosperm leaves [7].

\section{CONCLUSION}

Mesogenous stomata in which the subsidery cell have the cooon origin with guard cells. Other is the Perigenous which develop from the protodermal cells. Crucuferious type show that guard cells are surrounded by three subsidery cells of unequal size. Paracytic type show that guard cells accompanied by one or more subsidiary cells parallel to axes. Diacytic type in which stomata surround by the two subsidery cells. These shapes of the cells are shown under the microscope.

\section{REFRENECES}

1. Larkin, J. C., Marks, M. D., Nadeau, J., \& Sack, F. (1997). Epidermal cell fate and patterning in leaves. The Plant Cell, 9(7), 1109.

2. Naeem, M., Hayat, M., Qamar, S. A., Mehmood, T., Munir, A., Ahmad, G., Azmi, U.R., Faryad, M. A., Talib, M. Z., Irfan, M., Hussain, A., Hayder, M. A., Ghani, U., Mehmood, F., (2019). Risk factors, genetic mutations and prevention of breast cancer. International Journal Bioscience, 14(4), 492-496.

3. Borchert, R., Robertson, K., Schwartz, M. D., \& Williams-Linera, G. (2005). Phenology of temperate trees in tropical climates. International Journal of Biometeorology, 50(1), 57-65.
4. Kenrick, P., \& Crane, P. R. (1997). The origin and early evolution of plants on land. Nature, 389(6646), 33.

5. Ahmad, I., Khan, S., Naeem, M., Hayat, M., Azmi, U. R., Ahmed, S., Murtaza, G., \& Irfan, M. (2019). Molecular Identification of Ten Palm Species using DNA Fingerprinting, International Journal Pure Applied Bioscience, 7(1): 46-51.

6. Sack, F. D., \& Paolillo Jr, D. J. (1985). Incomplete cytokinesis in Funaria stomata. American Journal of Botany, 72(9), 1325-1333.

7. de Boer, H. J., Price, C. A., Wagner-Cremer, F., Dekker, S. C., Franks, P. J., \& Veneklaas, E. J. (2016). Optimal allocation of leaf epidermal area for gas exchange. New Phytologist, 210(4), 12191228.

8. Acharya, B. R., \& Assmann, S. M. (2009). Hormone interactions in stomatal function. Plant molecular biology, 69(4), 451-462.

9. Rudall, P. J., Hilton, J., \& Bateman, R. M. (2013). Several developmental and morphogenetic factors govern the evolution of stomatal patterning in land plants. New Phytologist, 200(3), 598-614.

10. 7Ahsan, M., Aslam, M., Akhtar, M. A., Azmi, U. M., Naeem, M., Murtaza, G., Irfan, M., \& Shafiq, S., (2019). Effect of inoculation of three rhizobial strains on maize hybrids. Journal Bio Environment Science, 14(6), 168-177.

11. Shafiq, S., Adeel, M., Raza, H., Iqbal, R., Ahmad, Z., Naeem, M., Sheraz, M., Ahmed, U., \& Azmi, U. R. (2019). Effects of Foliar Application of Selenium in Maize (Zea MaysL.) under Cadmium Toxicity. Biological Forum-An International Journal, 11(2): 27-37.

12. Verhertbruggen, Y., Walker, J. L., Guillon, F., \& Scheller, H. V. (2017). A comparative study of sample preparation for staining and immunodetection of plant cell walls by light microscopy. Frontiers in plant science, 8, 1505.

13. Pillitteri, L. J., Sloan, D. B., Bogenschutz, N. L., \& Torii, K. U. (2007). Termination of asymmetric cell division and differentiation of stomata. Nature, 445(7127), 501-505. 